\title{
A MOBILE USER INTERFACE FOR LOW-LITERACY USERS IN RURAL SOUTH AFRICA
}

EDIM A. EMMANUEL AND HIPPOLYTE N. MUYINGI

\begin{abstract}
Information and Communication Technology services for socio-economic development of low-literacy users in rural communities in developing regions are new research contributions that seek to alleviate poverty in underserved communities. The intended users are still new to these technologies and can be described as novice users. This study was conducted to design a mobile user interface to enable low-literacy users in Dwesa community in South Africa to have access to mobile commerce services. We applied different ethnographic research methods through a usercentred design approach to actively involve the target users in the design process. This helped to identify the usersô needs and also meet usersôexpectations. The usability of the mobile user interface was evaluated with the target users in the community. The user evaluation shows that the users have positive attitudes and perception of the system. The study found that the user interface conforms to the usersôcultural experience and preferences and they are also positive in their intent to use the user interface.
\end{abstract}

\section{INTRODUCTION}

Rural communities in developing countries often lack basic socio-economic infrastructure to alleviate their living standards. The communities are underserved and lack basic government provided infrastructures. In the research community, Information and Communication Technology (ICT) have been recognized as viable platform for socio-economic development and poverty alleviation in underserved communities (Heeks, 2008). Notable areas for ICT implementations in rural communities include products and services in education, health care, socio-economic development, government information and services. These ICT services and others will bring positive impact and improve rural livelihood. The introduction of these technologies in rural communities is not without challenges such as technology illiteracy, low literacy level and cultural barriers.

In order to overcome these challenges, understanding of the usersôsocio-cultural environment and preferences is required. During the design ICT products and services for low-literacy users, adequate attention must be given to these concerns and other problems that might impede the usability of these services. This will help to achieve the anticipated goals of the project. No doubt these technologies in most cases may be new to the people, their cultural background and their capabilities. The design of a user interface that conforms to the socio-cultural environment of the users, their capabilities and preferences will play a significant part in the usability of the user interface, increase user experience and make the technology acceptable to the people.
The objectives for implementing ICT projects in rural underserved communities are to promote socioeconomic development and poverty alleviation among the people. Such systems must conform to the experience and capabilities of the people, and also meet their needs and expectations (Lalji and Good, 2008). Any design that goes contrary to these will result to user interfaces and systems that are not usable and users will spend more time struggling to conform to the systems (Marcus, 2001). Usability and user experience are key ingredients for a successful implementation of ICT services and mobile applications (Hassanein and Head, 2003), even for rural users.

New technology users in rural community are usually influenced by their socio-cultural environment. This is their everyday living which also has an influence on how they use technology. They also lack experience with technology and interaction with user interfaces. These groups of users need services and user interfaces that are easy to use, intuitive and conform to their rural way of life. The application of ethnographic research methods through a user-centred design approach enable even low-literacy users to be fully involve in the design process. The interactions usually provide useful information that will produce a user interface that is accessible to the target users irrespective of their capabilities and experience with technology.

This paper presents the study that lead to the design of a mobile commerce application and a localized mobile user interface for micro-entrepreneurs in a rural community in South Africa. We adopted the technology acceptance model (TAM) constructs to examine the usersôattitudes towards the localized user interface. The

Edim A. Emmanuel, Department of maths/Stats and Computer Science, University of Calabar, Calabar, Nigeria Hippolyte N. Muyingi, Department of Software Engineering, the Polytechnic, Namibia. 
result of the descriptive statistical analysis of user data is also presented and conclusions made.

\section{Related Work}

Information and Communication Technology have become the catalyst for $21^{\text {st }}$ century businesses. ICTs provide sustainable development even in developing countries. ICTs have penetrated every aspect of human life (Heeks, 2008). The mobile phone is a good example of ICT product that is delivering electronic services to micro-entrepreneurs in developing countries. These ICT devices serve as media for improving businesses and also for satisfying user intrinsic needs (Donner, 2004). Despite the achievements recorded by small business owners with the mobile phone in developing countries, the vast majority of ICT projects for development are still concentrated in urban centres (Batchelor and Scot, 2005). The rural communities are still not considered as viable markets for ICT deployments. The rural communities in developing countries are alleged to be risky markets and are yet to be fully explored to a large extent (Heeks, 2008). Research has revealed the significant impact of ICTs on the economic growth of businesses in developed countries where they have been deployed and used successfully (Dedrick et al., 2003).

Mobile networks have reached several rural communities providing mobile connectivity to the rural inhabitants (ITU, 2007) as a result of the increasing demand for mobile telecommunication. Mobile telecommunication has greatly narrowed the digital gab that was created as a result of the absence of desktop computers in rural communities in developing countries. Africa accounts for the highest mobile phone subscription rate in the world (World Bank report, 2009). Users of mobile phone now have provision and opportunity to have access to information and ICT services from the Internet (WAP and HTTP enabled mobile phones), and do not need to worry and wait till they are able to afford a desktop computer before being connected. Low-literacy mobile phone users in rural underserved communities can be provided with mobile ICT services for socio-economic development. These services can be accessible with user interfaces that conform to the usersô socio-cultural environment and preferences and improve the usability and experiences of the users.

The use of ICTs for socio-economic development of low-literacy and poor people in developing countries have shown positive impact among the people where they have been implemented, mainly in Asia. These research efforts include computer literacy programmes and ICT services in health, education, microfinance and others. All these research efforts had made attempt in making ICT services accessible to lowliteracy users by developing the services and user interfaces that are easy to use by the target users. Medhi et al. (2006) designed a text free user interface on desktop computers to enable semi and illiterate domestic labourers in India to find jobs within their community on the Internet. The user interface presented static diagrams that depict job activities recognizable by the users. This is similar to the work carried out in this study but differed on the platform of implementation. The target users used the user interface successfully to access information on the Internet. Patel et al. (2008) describes a mobile phone voice user interface developed for rural Indian farmers and to enable the farmers share farming information within their community. Sherwani et al. (2007) present an online desktop application prototype developed to assist rural low-literacy community health workers in Pakistan. The Internet based application helps the rural health workers to access health information from the Internet and applies the information on their job to improve the delivery health care in the rural areas.

A mobile user interface that enables members of Self Help Group in a rural community in India to manage their finances is described in Gosh et al. (2003). The users formed a microfinance group and use the user interface to save and lend money to members and also help the users access their account and attract government support with the help of the interface. The users were semi-illiterate rural community members. The application environment and user group have similar characteristics to the environment and user group in this study. The application domain and the input into the user interface are different from this study. Cremers et al. (2008) discussed user-centred design processes by studying user interfaces of ATM machines with the involvement of illiterate persons. The study gave account on the techniques that will allow adequate participation of semi-illiterate persons during the design of user interfaces that will meet user requirements for semi-illiterate persons.

A study was conducted on 28 different games played by low-literacy rural children in India in order to design a digital videogame application by $\mathrm{Kam}$ et al. (2009). In designing the mobile game application and user interface, the authors applied ethnographic studies to elicit the tasks requirements for the game and user interface. The authors fashioned out the interaction requirements based on their decisions as a means of adding flexibility, intuition and increase user experience.

In order to design suitable user interface for illiterate people, Medhi et al. (2009) performed a study to find a user interface type that will be easy and intuitive to illiterate users and help the users to access financial services. The authors also tried to determine user interface preference among illiterate users and they found that illiterate users performed better with spoken dialog interfaces than text-based interfaces. Illiterate users also preferred the spoken dialog interface to the text-based interface. Medhi et al. also found that the illiterate users performed tasks at a very high level with multimedia user interfaces.

Speech versus Dual-Tone Multi-Frequency (DTMF) input voice interface designed for low-literacy users is discussed in Patel et al. (2009). The study compared usersô performers using the speech versus DTMF input interfaces. The researchers found that lowliteracy users performed better with DTMF input as compared to the voice input.

A study carried out to determine user interface representations that can assist illiterate and semiilliterate users in speedy understanding of health information is presented in Medhi et al. (2007). Medhi et 
al. found that usersô comprehension is better when presented with voice annotations and hand drawn graphics on the user interface.

A mobile phone user interface for semi-illiterate users in rural communities in India is described in Parikh et al. (2006). The user interface enables the users to use their mobile phones to capture data from paper documents through the camera of their mobile phone. The camera reads visual codes on the paper documents to give details of the financial status of the user. The user interface known as CAM is intuitive, flexible and easy to use for interactions. The user do not need to read information on the documents but rather, the phone reads the visual codes and the application does the interpretation and give the user the required information.

A study that looked at user performance and preference for speech versus touch-tone user interface among low-literacy community health workers in rural Pakistan was conducted by Sherwani et al. (2009). The study found that low-literacy participants performed better with the spoken dialog interface than the touchtone interface.

Research had shown that ICT services can be used to empower low-literacy users in rural communities both socially and economically. Mobile phone penetration in rural underserved communities has brought an accessible technology platform to the rural people. The implication is that the digital gap created as a result of the absence of personal computers in rural communities is gradually diminishing. Mobile ICT services (such as mobile commerce) targeting the rural community people would be accessible using mobile phones. It will enable information flow between the rural communities and the outside world.

Research efforts towards the use of ICTs for empowering low-literacy users in rural communities in developing countries had shown positive contributions to the socio-economy of the people. These efforts have not reached the vast majority of African rural communities. The user interfaces for mobile ICT services will play a major part in encouraging low-literacy users to adopt ICT services into their socio-economic activities.

\section{Methodology}

ICT projects or services targeting low-literacy users in rural areas are usually initiated by designers or researchers from different environments or background. The development process may solely rely on the decisions of the initiators who may not have the same cultural influence or challenges like the target users. The final product may tilt to the designerês perspective and experience rather than the users. In rural areas, users often do not posses any experience in the technology and may find it difficult to make meaningful contributions to the design of the application and user interface (Edim and Muyingi, 2010a). They also find it difficult to form a user model of the intended application (Isabirye and Flowerday, 2008). It is evident that when the users are given the opportunity to participate in the design process a successful and acceptable system will emerge (preece et al, 2002). For this reason, we applied a user centred design approach in this study.

We adapted the user centred design approach to meet up with the user environment and the characteristics of the target users. Within this approach various research methods were applied to ensure effective user participation. The user centred design approach consists of the following phases:

i. User/environment study - This phase involved determining the user characteristic, user needs and the cultural environment. We conducted onsite visits and informal interviews with community members. A survey was also carried out to gather substantial amount of qualitative and quantitative data. The survey consisted of positively rated Likert-scale questions with a point scale of 1-5. The questionnaires were distributed by simple random sampling to community members and a total of 120 responses were received from the respondents.

ii. Tasks analysis and scenario design - At this point the emphasis was to identify the user tasks for the user interface and the mobile commerce system functions. We conducted an audit of similar applications and user interfaces and gathered data for scenarios design and formative evaluation. Focus group was organized in the community with the help of a community facilitator for formative evaluation of the scenarios and data gathering. 9 crafters took part in the evaluation in Ngwane art and craft center in the community.

iii. Prototype design and evaluation - Prototype in the early stage of system development helps the users to form a mental model of the system and facilitate the process of eliciting user requirements. The prototype application and user interface were designed and formative evaluation sessions were performed through focus groups in the community. 12 school learners in grade 11 and 12, and 7 crafters with an average age of 42 years participated in the evaluation. During the process data were elicited from the participants. The data include images of crafted products from the crafters, and user interface interaction preferences.

iv. Cultural adaptation of user interface - In order to adapt the user interface to a culture sensitive user interface, we conducted different research methods that include audit of the cultural environment, interviews with community members and survey. During the audit of the environment, we surveyed the environment to identify artefacts within the cultural environment that the people of Dwesa interact with on daily basis within and outside their homes. Images of these artefacts were captured, evaluated, and validated with experts who were also computer literate. The survey consists of the Value Survey Module (Hofstede et al. 2008) questionnaires which were distributed to the literate members of the community. Oral interviews were conducted in the community by visiting participants in their homes.

v. Design evaluation: the user interface was evaluation through focus groups method and single user evaluation. Focus groups consist of 12 school learners in the $11^{\text {th }}$ and $12^{\text {th }}$ grades with an average age of 17.5 years. 11 crafters 
constituted the second focus group made of 7 semi-illiterates and 4 illiterates. The average age of the crafters was 48 years. The third focus group consists of 9 clerical staff in the community schools. Their average age was 36 years. During single user evaluation, 10 educators from the community schools participate in the evaluation on individual basis. Their average age was 38 years. All the participants were given a post-test questionnaire to fill at the end of each evaluation session.

\section{Data Analysis and Results}

There is generally low level of ICT awareness in the community and as such the design process was very tasking. Mobilizing the community members to participate was also difficult. The distance between the researchers and the community also created its challenges. This made the process of designing and user participation more difficult. The presentation of this study results is done following the approach adopted in the methodology.

\section{User Environment}

Based on the survey conducted, the occupation distribution include: Farmers, women engaged in art and craft, school learners, teachers (educators), none teaching staff in schools and the unemployed. The mean age distribution of the respondents was 35 years. 77.4 percent of the respondents owned mobile phones. The mean years of using a mobile phone by respondents was 2.6 yrs. Figure 1 represents the technology literacy (awareness and use of technologies) in the community.

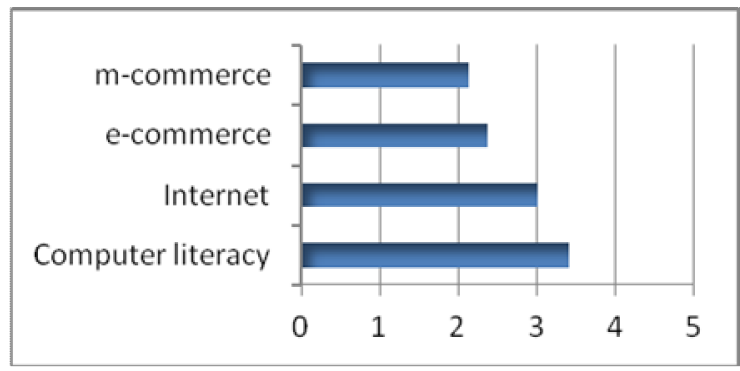

Figure 1. ICT technologies awareness and use

On a point scale of 0 ï 5, respondents who are aware or have used mobile commerce were less than 2.5 points and those who are aware or have used the Internet scored 3 points. The graph shows a low level of awareness and use of the different technologies in the graph. These users are not very familiar with modern ICTs. The implication on the user interface design is that it will be difficult for these users to make good contribution in pointing out what they want or state what their requirements are. The technology landscape indicates that the Dwesa people are novice technology users. These groups of users need user interfaces that are simple and easy to understand. The user interface should be able to conform to their cultural environment so that it will present features that are easy to understand and use.

Business activities within the community were very low. The inhabitants in the community depend on the market in the nearby town (Wilowsvale), which is a distance of $40 \mathrm{~km}$ on a rough un-tarred road to purchase their household needs. They also take any produce or products from the community to this market if they have to sell and at the same time bear the cost of transportation. Lack of basic infrastructures and poverty has caused the local market not to develop. This situation further discourages the local microentrepreneurs from developing their trade.

\section{Task Analysis}

An audit of similar and existing e-commerce and m-commerce applications helped in identifying user tasks and user interface interactions and activities. The best solutions were selected and applied in designing two separate sets of goals and user tasks. One is the set of tasks the customer will perform to achieve the goal of purchasing an item from the online shop. The other set of tasks are the ones the shop-owners will perform to achieve the goal of managing their on-line shops. Figure 2 illustrates an upper level tasks tree for shop-owner interactions. 


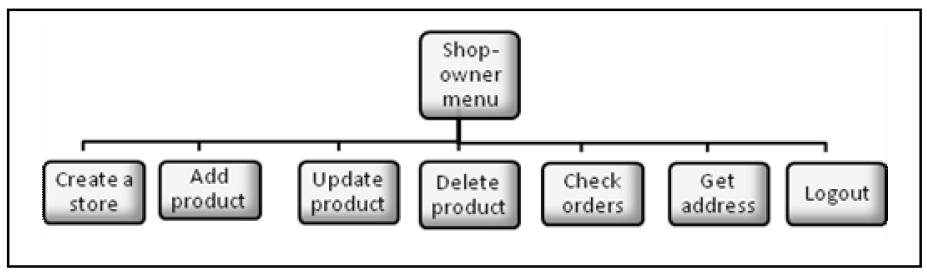

Figure 2. Shop-owner tasks tree

\section{Prototype Design}

The prototype provides two different user interfaces for interaction, one for the customers wishing to interact with $\mathrm{m}$-commerce application and the other for the shop-owners to enable them manage their online shops. The customer will interact with a graphical user interface to carry out tasks that include registering and placing an order for items. On the other hand, the shopowner is presented with a localized user interface that allows him/her to manage the online shop. The shopowner tasks include: creating a new online shop, add a product to the online shop, update an existing item in the shop, remove a product from the shop, Check for any existing order made by a customer, etc. Some of these actions are initiated using a button or selecting a graphical icon on the screen. Usersô evaluation data were collected and used to refine the prototype. Figure 3 shows screen shots of the prototype. Figure 3(a-d) shows the home page of the m-commerce application and user interface in one of the online shop and its products, products in a shopping basket (3c), and the shop-owner user interface respectively. Figure $3 d$ is a localized user interface for the local shop-owners.

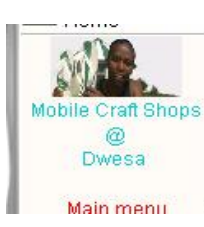

a

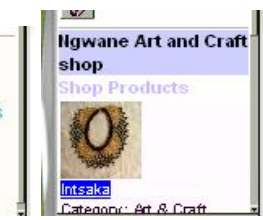

b

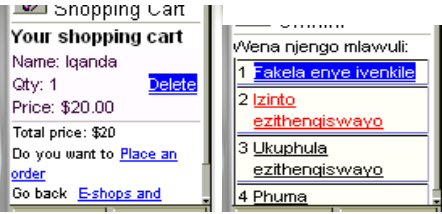

d

Figure 3. (a) Home page, (b) An online shop, (c) Shopping basket, (d) Shop-owner interface.

\section{Cultural Adaptation of User Interface}

Cultural differences exist among different people and regions. Culture influences design decisions, usersô perspective and the artefacts used on the interface (Smith et al., 2004). Good design of cultural interface elements with usersôpreferences will improve usability of the system (Marcus, 2001; Shen et al., 2006, W3C, 2009), and also a means of bringing technology to communities that are technology illiterates (Yeo, 1996). The value survey module provided data on culture dimensions of Dwesa people. The results are presented in Table 1. Hofstede $\hat{\mathbb{s}}$ dimensions of culture (Hofstede, 2008 include Power-distance, Collectivism vs. Individualism, Femininity vs. Masculinity, Uncertainty avoidance.

The cultural dimensions of Dwesa people and other findings are presented in Table 1. Dwesa is a moderate power distance society. The implication on the user interface design is that the people will embrace interface elements that represent their national symbol, their heroes, and artefacts that depict their national monuments. It is a collective society. The implication is that the people will prefer user interfaces that bring out their collective value systems. The Dwesa society is a collective one and as such, the people will want user interface elements that represent family values rather than individual values. The uncertainty avoidance dimension is high. The implication on user interface design is that the people will prefer user interface elements that are not complex, a menu system that is short devoid of high hierarchies, information on interface that does not have hidden meaning and interaction elements that represents their culture. They prefer user interface elements to be in a language that they are familiar with and simple to recognize and understand. Dwesa is also a masculinity society and the implication on user interface is that interface elements that are gender sensitive will not be attractive to the people. Table 2 presents cultural preferences of the people in Dwesa community. These preferences are what the participants felt it would help to make the user interface simple and easy to understand. For instance, different colors have their meaning and what they symbolize in the society. The black color represents a state of soberness/evil and will easily repel the people. The yellow color is a national color and is generally accepted. The brown color is used for decoration and represents strength. Table 3 shows some of the 
identified cultural metaphors/icons used on the interface. These interface markers were used as static diagrams to represent user interface metaphors/icons. These artefacts represent cultural artefacts found within the cultural environment of the Dwesa people. The mobile device is limited in size and capabilities and as such limited amount of graphics is recommended to reduce the weight on the interface, and the cost on the user.

Table 1: Culture dimensions of dwesa community.

\begin{tabular}{|c|c|}
\hline Dimensions & Findings \\
\hline $\begin{array}{l}\text { Power-distance (rating }=66.5 \text { ): } \\
\text { moderate }\end{array}$ & $\begin{array}{l}\text { High level of poverty } \\
\text {. Lack of basic infrastructures } \\
\text {. existence of inequality between urban and rural life } \\
\text {.high dependent on social grants }\end{array}$ \\
\hline $\begin{array}{l}\text { Collectivism vs. individualism (rating } \\
=68 \text { ): strongly collective }\end{array}$ & $\begin{array}{l}\text { People are identified by their families } \\
\text { they live according to kinship } \\
\text { they depend on one another for support and growth } \\
\text {. common social and religious groups }\end{array}$ \\
\hline $\begin{array}{l}\text { Femininity vs. masculinity (rating }=- \\
\text { 24.5): masculinity }\end{array}$ & $\begin{array}{l}\text { Men are heads of family } \\
\text { Men are the decision makers in a family } \\
\text { Men provide support and security to the family }\end{array}$ \\
\hline $\begin{array}{l}\text { Uncertainty avoidance (rating = } \\
\text { 122.5): high uncertainty avoidance }\end{array}$ & $\begin{array}{l}\text { Friendly, tolerant and easy-going people } \\
\text { highly religious society } \\
\text { living influence by culture and religion } \\
\text { Avoid taking risk }\end{array}$ \\
\hline
\end{tabular}

Table 2: Users cultural preferences

\begin{tabular}{|l|l|}
\hline Cultural attractors & Findings \\
\hline Colors & $\begin{array}{l}\text {. White color - regarded as a culturally preferred, } \\
\text { represents purity, used in traditional attires. } \\
\text {. Black color- used in traditional attire, represents evil, } \\
\text { bad. } \\
\text {. Brown color ï used for decoration } \\
\text {. Red represents danger. }\end{array}$ \\
\hline Text & . Prefers text presented in Isixhosa language \\
\hline Numbering & $\begin{array}{l}\text {. Count with normal numbering system (1, 2, 3,..) } \\
\text {. Traditional numbering system Ï I, II, III, IIII, é }\end{array}$ \\
\hline Interaction type & $\begin{array}{l}\text {. Voice in local language most easiest to understand } \\
\text {.Graphics interface with local and easy to understand } \\
\text { symbols. }\end{array}$ \\
\hline Menu layout & $\begin{array}{l}\text {.familiar with hierarchical } \\
\text {.list presentation } \\
\text {. central positioning }\end{array}$ \\
\hline Labels and buttons & $\begin{array}{l}\text {. Labels in local language } \\
\text {. Button text in local language }\end{array}$ \\
\hline Images and graphics & . use of cultural graphics to represent actions \\
\hline Help item & . provide short help to assist navigation \\
\hline
\end{tabular}


Table 3: Cultural metaphors/icons

\begin{tabular}{|l|l|l|}
\hline Function & Metaphor & Meaning \\
\hline Home & $\begin{array}{l}\text { A local hot is a residence, can be used to represent the } \\
\text { home page/command }\end{array}$ \\
\hline $\begin{array}{l}\text { Forward } \\
\text { backward }\end{array}$ & An arrow sign represent navigation \\
\hline Entry/exit & & A door can represent a point of entry and exit \\
\hline Add & & $\begin{array}{l}\text { A tray for collecting items and represents a container for } \\
\text { addition of items }\end{array}$ \\
\hline Delete & A trash can represent disposal of items \\
\hline
\end{tabular}

The information on the tables (Table 1,2 and 3) was used to adapt the mobile user interface to a culture sensitive user interface. The interface elements depict what is familiar to the users within their cultural environment. These are the interaction elements that the users interact with on daily basis within and outside their homes. These include the language of the interface, the cultural metaphors/icons, color markers, text, interface layout, buttons and menu.

\section{User Evaluation}

The shop-owner user interface was evaluated by participants in the community. Each of the participants performed selected tasks while we observed and took record of our observations. At the end, we gave out post-test questionnaires (Likert-scale) and interviewed participants as well. The questions centers on perceived usefulness of localization, perceived usefulness, perceived ease of use and perceived intention to use the system.

We adopted the technology acceptance model (TAM) constructs (Davies, 1989) to design the post-test questionnaire and test usersôperceptions of the system. TAM was used by Evers and Day (1997) to evaluate cultural preferences among users of globalised software. Also, Aggelidis and Chatzoglou (2009) applied TAM constructs to test usersô behavior towards an e- commerce application. Table 4 presents the results of usersôperception.

The result shows that participants have a high perception towards the system. The users were positive in perceived usefulness of localization and ease of use with mean scores of 3.59 and 3.75 respectively. They see localization as a means of making the user interface to conform to their cultural environment and making it easy for them to interact with the interface. The users were also positive in the rating of perceived usefulness and perceived intention to use the system with mean scores above 4 respectively. The users feel that the user interface and application are useful to their community and are positive that they are going to use the system. The positive rating of all the constructs shows that the user interface was easy to understand and use. Cultural adaptation of the user interface had made the artifact to conform to what the people are familiar with. The correlation coefficient of perceived usefulness of localization, ease of use, usefulness of interface indicates that there exist a positive correlation between these constructs and intention to use the system. The participants were first time users who were not very familiar with the process of evaluation and the technology. Based on the results, the users were able to use the user interface and are positive in the intention to use the user interface and application. 
Table 4 - mean scores of user perception of the system (five points scale:5 = strongly agree; $4=$ agreed; $3=$ neutral ; $2=$ disagree; 1 = strongly disagree)

\begin{tabular}{lllll}
\hline Participant \# & $\begin{array}{l}\text { Usefulness } \\
\text { localization }\end{array}$ & $\begin{array}{l}\text { of } \\
\text { usefulness }\end{array}$ & $\begin{array}{l}\text { Perceived } \\
\text { of use }\end{array}$ & $\begin{array}{l}\text { ease } \\
\text { uscerceived } \\
\text { Intention to use }\end{array}$ \\
\hline 1 & 5.00 & 4.33 & 3.71 & 4.00 \\
2 & 5.00 & 5.00 & 2.71 & 4.67 \\
3 & 3.33 & 5.00 & 3.00 & 4.67 \\
4 & 4.67 & 5.00 & 2.86 & 5.00 \\
5 & 4.33 & 4.67 & 4.57 & 5.00 \\
6 & 2.50 & 3.33 & 3.43 & 4.33 \\
7 & 4.67 & 4.33 & 3.00 & 4.67 \\
8 & 2.67 & 5.00 & 4.00 & 4.00 \\
9 & 3.00 & 5.00 & 4.57 & 4.33 \\
10 & 3.00 & 5.00 & 4.71 & 4.33 \\
11 & 3.00 & 5.00 & 4.71 & 4.33 \\
12 & 4.33 & 4.00 & 3.875 & 4.67 \\
13 & 4.00 & 4.00 & 3.71 & 4.67 \\
14 & 4.00 & 4.00 & 3.43 & 1.00 \\
15 & 4.00 & 4.67 & 3.71 & 4.00 \\
16 & 4.00 & 4.67 & 4.14 & 4.33 \\
17 & 4.00 & 4.00 & 3.71 & 4.33 \\
18 & 4.00 & 3.33 & 4.29 & 4.67 \\
19 & 3.50 & 3.50 & 3.29 & 3.00 \\
20 & 2.00 & 4.00 & 3.14 & 3.67 \\
21 & 2.33 & 3.33 & 4.00 & 4.67 \\
22 & 2.33 & 3.67 & 3.83 & 3.67 \\
23 & 3.00 & 5.00 & 3.71 & 4.33 \\
Mean & 3.59 & $\mathbf{4 . 3 4}$ & $\mathbf{3 . 7 5}$ & $\mathbf{4 . 1 9}$ \\
SD & $\mathbf{0 . 8 7}$ & $\mathbf{0 . 6 1}$ & $\mathbf{0 . 5 7}$ & \\
Correlation & $\mathbf{0 . 1 5}$ & $\mathbf{0 . 2 5}$ & $\mathbf{0 . 1 3}$ & \\
intention to use & & & & \\
\hline & & & & \\
\hline
\end{tabular}

In the evaluation process, the participants were given two tasks to perform. The first tasks involved creating an online shop. The subtasks include selecting the menu, and entering the user name and password, and then the name of the shop and the type of products to present in the online shop. The second task involved adding two products into the newly created shop. The subtasks include selecting the shop from the list, and adding the products and the relevant fields that describe the products. Figure 4 presents the tasks completion rate among the different user groups in the community. 


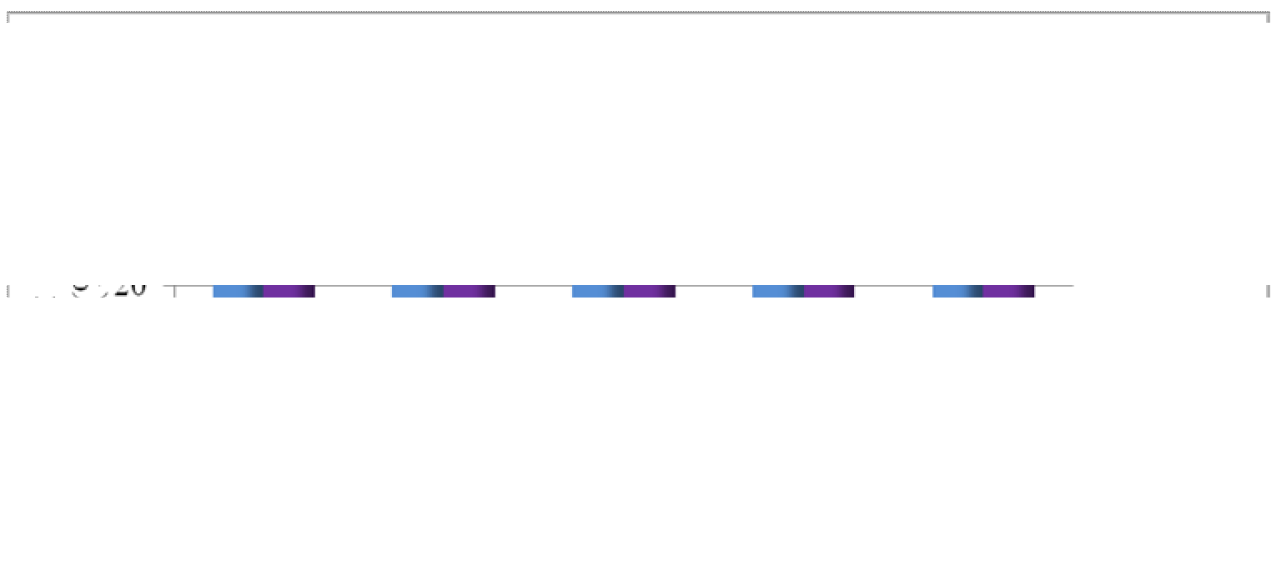

Figure 4: User tasks performance success rate

The results show that the users irrespective of their literacy and technology awareness levels, they were able to interact with the user interface successfully. There was more than $50 \%$ tasks completion success rate among the different user groups for the two selected tasks. The crafters despite the low-literacy level performed very well and recorded more than $50 \%$ successes. The study found that the users were able to identify the user interface elements, and easily navigate through the interface to perform the tasks. The user interface elements meet the user preferences and cultural experiences. The study also found that the user experience will continue to improve as the users continue to use the interface. This is indicated in the level of task successes recorded when the users performed the second task after the experience the gathered from performing the first tasks. This is an indication that the users found the user interface simple to use and easy to understand. There was high level of precision in tasks performance among the different user groups. The study found that the users were familiar with the interaction elements on the user interface and as such it was easy for them to interact with the interface with ease.

\section{CONCLUSION}

The proliferation of mobile phones to rural communities has made media accessibility possible for low-literacy users in developing countries. Mobile phones can be used to access information at anytime and anywhere. Low-literacy users in rural community will adopt ICTs when user interfaces required to interact with
ICT services meets their cultural experience and preferences. In this study, we have designed a mobile user interface to enable low-literacy rural microentrepreneurs to interact with a mobile commerce application. The study found that the target users are willing to adopt the application and user interface for their economic advantage. The user-centered approach and research methods applied in this study enabled users to be involved in the development process. The research methods used were adapted to suit the culture and the environment of the target users for effective participation and to achieve the desired results (Smith et al. 2004). This is because; in rural communities these technologies and user interface design processes are still novel to the users. The user interface has been customized to create a sense of belonging and facilitate technology acceptance (Yeo, 1996).

The study results show that the users have positive perception of the user interface and intent to use the system. This study has provided evidence that cultural adaptation of user interfaces and interactions will support effective use of ICT services. This is because the process had helped to capture the needs and cultural experiences of the target users and created an artifact that meets the expectations of the users. This implies that cultural issues that influence the behaviours, motivations and attitudes of the users are very important in the design of a user interface targeting a given cultural group. This study is also an attempt to show that mobile commerce can be used for socioeconomic development of the rural communities in the long run.

Further research is expected to include more cultural artefacts and enhance the user interface further. Also, more study is required to test the user interface presentation across different mobile devices. 


\section{REFERENCES}

azAggelidis, V. P. and Chatzoglou, P. D., 2009. Using a Modified Technology Acceptance Model in Hospitals, Int $\widehat{\emptyset}$ Journal of Med. Informatics, 78: 115-126.

Batchelor, S., and Scott, N., 2005. ICTs for economic growth and poverty reduction. The DAC journal, 6: 3.

Cremers, A. H. M., de Jong, J. G. M., and van Balken, J. S., 2008. User-Centred Design with Illiterate Persons: The Case of the ATM User Interface. In: proc. of International Conference on Computers for Handicapped Persons, 713-720.

Davies, F. D., 1989. Perceived usefulness, perceived ease of use, and user acceptance of information technology, MIS Q. 13,3, 319-340, in: Aggelidis, V. P. and Chatzoglou, P. D. (2009) Using a Modified Technology Acceptance Model in Hospitals, Int市 Journal of Med. Informatics, 78: 115-126.

Dedrick, J., Gurbaxini, V., and Kraemer, K., 2003. Information technology and economic performance: A critical review of the empirical evidence, ACM Computing Surveys, 35(1): 1-28.

Donner J., 2004. Micro-entrepreneurs and Mobiles: An Exploration of the Uses of Mobile Phones by Small Business Owners in Rwanda. Centre for Global Health and Economic Development. The Earth Institute at Columbia University. New York. Information Technologies and International Development, 2(1): 1-21.

Edim, A. E. and Muyingi, H. N., 2010a. A Cultural User Interface for a Rural Community in South Africa, Proceedings of SATNAC-2010, Stellenbosch, South Africa, pp.231-236.

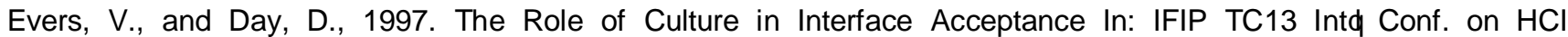
INTERACT囚7, Chapman \& Hall, London, Sydney, Australia. In: Shen S., Woolley, M. and Prior S. (2006) Towards Culture-centered Design, Interacting with Computers, 18: 820-852.

Ghosh, K., Parikh, T. and Chavan, A., 2003. Design Considerations for a Financial Management System for Rural, Semi-literate Users, ACM Conference on Computer-Human Interaction-2003.

Hassanein, K. and Head, M., 2003. Ubiquitous usability: exploring mobile interfaces within the context of a theoretical model, Ubiquitous Mobile Information and Collaboration Systems Workshop (UMICS 2003), The 15th Conference on Advanced Information Systems Engineering, Velden, Austria.

Heeks, R., 2008. ICT4D 2.0: The Next Phase of Applying ICT for International Development. Computer, 41(6): 26-33.

Hofstede, G., Hofstede, G.J., Minkov, M. and Vinken, H., 2008. Values Survey Module 2008 Questionnaire. Available : http://www.geerthofstede.nl/research--vsm/vsm-08.aspx, (Accessed: 24 November, 2009)

Hofstede, G. and Hofstede, G.J., 2005. Cultures and Organizations: Software of the Mind Revised and expanded 2nd Edition. New York: McGraw-Hill USA. ISBN 0-07-143959-5.

Isabirye, N. and Flowerday, S., 2008. A model for eliciting user requirements specific to South African rural areas, ACM International Conference Proceeding Series; Proc. of the 2008 annual research conference of the South African Institute of Computer Scientists and Information Technologists on IT research in developing countries: riding the wave of technology ,Wilderness, South Africa, 338:124-130.

ITU International Telecommunication Union, 2007. Measuring Village ICT in Sub-Saharan Africa. Available: www.itu.int/ITU-D/ict/statistics/material/Africa_Village_ICT_2007.pdf. (Accessed: 10th July, 2008)

Kang, K. and Corbitt, B., 2001. Effectiveness of Graphical Components in Web Site E-commerce Application ï A Cultural Perspective. Electronic Journal of Information Systems in Developing Countries, 7(2): 1-6.

Kam, M., Mathur, A., Kumar, A. and Canny, J., 2009. Designing digital games for rural children: a study of traditional village games in India, Proceedings of the 27th International Conference on Human Factors in Computing Systems, USA, pp.31-40.

Lalji, Z. and Good, J., 2008. Designing New Technologies for Illiterate Populations: A study in Mobile Phone Interface Design, Interacting with computers, 20: 574-586. 
Marcus, A., 2001. Cross-cultural user-interface design for work, home, play, and on the way. Proceedings of the 19th annual international conference on computer documentation Sante Fe, New Mexico, USA, pp.221-222.

Medhi, I., Prasad, A. and Toyama, K., 2007. Optimal Audio-Visual Representations for Illiterate Users of Computers, In Proceedings of International World Wide Web Conference Committee (IW3C2), WWW 2007, ACM 978-159593-654-7, Alberta, pp.873-882.

Medhi, I., Gautama S. N. N. and Toyama, K., 2009. A Comparison of Mobile Money-Transfer Uls for Non-Literate and Semi-Literate Users, Proceedings of CHI 2009, ACM Press, Massachusetts, pp.1741-1750.

Medhi, I., Sagar, A., Toyama, K., 2006. Text-Free User Interfaces for Illiterate and Semi-Literate Users. In: Proc. International Conference on Information and Communications Technologies and Development, pp.72-82.

Patel, N., Agarwal, S., Rajput, N., Kumar, A., Nanavati, A., Dave, P. and Parikh, T. S., 2008. Experiences Designing a Voice Interface for Rural India. In proceedings of the IEEE Workshop on Spoken Language Technology for Development (SLT), pp.21-25.

Patel, N., Agarwal, S., Rajput, N., Nanavati, A., Dave, P. and Parikh, T., 2009. A Comparative Study of Speech vs. Dialed Input Voice Interfaces in Rural India. ACM CHI-2009, Massachusetts, USA, pp.51-54.

Parikh, T., Javid, P., Sasikumar, K., Ghosh, K., and Toyama, K. 2006. Mobile Phones and Paper Documents: Evaluating a New Approach for Capturing Microfinance Data in Rural India, ACM Conference on ComputerHuman Interaction (CHI), Montreal, pp.551 - 560.

Preece, J., Rogers, Y., and Sharp, H., 2002. Interaction design: Beyond Human-computer interaction, John Wiley \& Sons, Inc., New York, In: Lalji, Z. and Good, J. (2008) Designing New Technologies for Illiterate Populations: A study in Mobile Phone Interface Design, Interacting with computers, 20: 574-586.

Shen S., Woolley, M. and Prior S., 2006. Towards Culture-centered Design, Interacting with Computers, 18: 820-852.

Sherwani, J., Ali, N. Mirza, S., Fatma, A., Memon, Y., Karim, M., Tongia, R. and Rosenfeld, R., 2007. HealthLine: Speech -based Access to Health Information by Low-literate Users. In Proceedings International conference of Information \& Communication Technologies and Development, Bangalore, India. Available: http://ww.cs.cmu.edu/ jsherwan/pubs/ictd07.pdf (Accessed: 20th October, 2008)

Sherwani, j., Palijo, S., Mirza, S., Ahmed, T., Ali, N., and Rosenfeld, R., 2009. Speech vs. Touch-tone: Telephony interfaces for Information Access by low literate users, Proceedings IEEE/ACM $3^{\text {rd }}$ Int. Conf. on ICTD, Doha, Qatar, pp.447-457.

Smith, A., Dunckley, L., French, T., Minocha, S., and Chang, Y., 2004. A Process Model for Developing Usable Crosscultural Web Sites, Interacting with Computers, 16: 63-91.

W3C (world Wide Web Consortium) 2009. W3C workshop Report: Thr Role of Mobile Technologies in Fostering Social and Economic Development, Maputo, Mozambique. Available: www.w3.org/2008/10/MW4D_WS/

World Bank report 2009. Connecting Africa: How ICT is Transforming a Continent. Available: PK:34370 piPK:34424 theSitePK:4607,00. html (Accessed: $28^{\text {th }}$ July, 2009).

Yeo, A., 1996. World-Wide CHI: Cultural user interfaces, a Silver lining in Cultural Diversity, SIGCHI, 28: 4-7. 